EKONOMIKAWAN : Jurnal Ilmu Ekonomi dan Studi Pembangunan

ISSN : $1693-7600$ (Print), ISSN : 2598-0157 (Online), http://jurnal.umsu.ac.ld/index.php/ekawan

\title{
Kemampuan Panel ARDL Memprediksi Ketahanan Fundamental Ekonomi Negara Muslim Emerging Market
}

\author{
Rusiadi \\ Universitas Pembangunan Panca Budi Jl. Gatot Subroto No.km, Simpang Tj., Kec. Medan \\ Sunggal, Kota Medan, Sumatera Utara 20122 \\ email : rusiadi@dosen.pancabudi.ac.id
}

\begin{abstract}
ABSTRAK
Tujuan penelitian membahas masalah penurunan ketahanan fundamental ekonomi negara Muslim Emerging Matket, baik jangka pendek maupun jangka panjang. Analisis data memakai Panel ARDL. Hasil penelitian menyimpulkan secara panel ternyata jumlah uang beredar menjadi leading indicator untuk pengendalian negara Indonesia, Bangladesh, Malaysia, Pakistan dan UEA, Arab Saudi, Turkey. Posisinya stabil dalam short run dan long run. Leading indicator utama efektivitas variabel dalam pengendalian ketahanan fundamental ekonomi negara emerging market Muslim yaitu investasi dilihat dari stabilitas short run dan long run, dimana jumlah uang beredar signifikan mengendalikan ketahanan fundamental ekonomi.
\end{abstract}

Kata kunci : Panel ARDL, Ketahanan Fundamental Ekonomi, kurs, PDB. 

Emerging Muslim Market Countries

\begin{abstract}
The objectives of the study discussed the issue of economic fundamental resilience of Emerging Matket, both short-term and long-term. Data analysis using ARDL Panel research results concluded in a Panel it turns out the amount of money supply to leading indicator for the control of Indonesia, Bangladesh, Malaysia, Pakistan and UAE, Saudi Arabia, Turkey. Its position is stable in short run and long run. Leading indicator of the effectiveness of variables in the control of the fundamental resilience of Muslim emerging market countries is the investment seen from the stability of short run and long run, where the amount of money supply significantly control durability Economic fundamentals.
\end{abstract}

Keywords: ARDL Panel, Fundamental durability economy, exchange rate, $G D P$

\title{
PENDAHULUAN
}

Ketahanan fundamental ekonomi diukur dari seberapa kuat variabel makro ekonomi berdampak oleh faktor internal dan faktor eksternal. Fundamental ekonomi bisa diukur dengan inflasi, kurs dan transaksi neraca perdagangan (Natsir,2014), Onyeiwu (2016) dan (Surjaningsih, 2015). Masalah yang sering terjadi terkait fundamental ekonomi adalah pertama ukuran yang tepat dalam menentukan indikator fundamental ekonomi mana yang paling mampu mewakili deteksi dini terjadinya pelemahan fundamental ekonomi suatu negara. Salah satu penyebab dampak penurunan ketahanan fundamental ekonomi dideteksi oleh efek tunda kondisi ekonomi. Hasibuan (2016), suku bunga sebagai indikasi fundamental ekonomi. Sheefeni (2013) menyebutkan kurs sebagai indikator kuat ketahanan fundamental, (Rusiadi; Novalina, 2018) menyatakan transmisi moneter mampu mengganggu stabilitas ekonomi. Anthony dan Ricard (2012) menyimpulkan cadangan devisa dan Verbeek (2011), Wimanda (2013) pertumbuhan ekonomi, net ekspor dan investasi. Sedangkan jasa keuangan diungkapkan sebagai indikasi ketahanan ekonomi suatu negara (Soares, 2011). Negara emerging market, khususnya negara Mulsim mendapat peran penting dalam menggerakkan ekonomi dunia. Fenomena masalah penelitian dilihat dari seperti PDB pada tabel 1.

Adanya penurunan pertumbuhan PDB negara Turki, Malaysia, Indonesia terjadi pada tahun 2015, pertumbuhan PDB Turkey turun menjadi 859,79 Milyar US\$ dari 934,18 Milyar US\$ tahun sebelumnya, Malaysia turun menjadi 296,43 milyar US\$ dari 338,06 US\$ tahun sebelumnya, dan Indonesia turun menjadi 861,85 Milyar US\$ dari 890,81 Milyar US\$ tahun sebelumnya. Penurunan ketahanan ekonomi oleh faktor pengeluaran pemerintah, investasi, inflasi (Oguanobi, 2014). Untuk meningkatkan ketahanan ekonomi, diperlukan kinerja ekspor stabilitas nilai tukar dan perluasan pasar non tradisional, termasuk perbaikan struktur ekspor komoditas (Ginting, 2015). 
Published July 2019

EKONOMIKAWAN : Jurnal Ilmu Ekonomi dan Studi Pembangunan

ISSN : 1693-7600 (Print), ISSN : 2598-0157 (Online), http://jurnal.umsu.ac.Id/index.php/ekawan

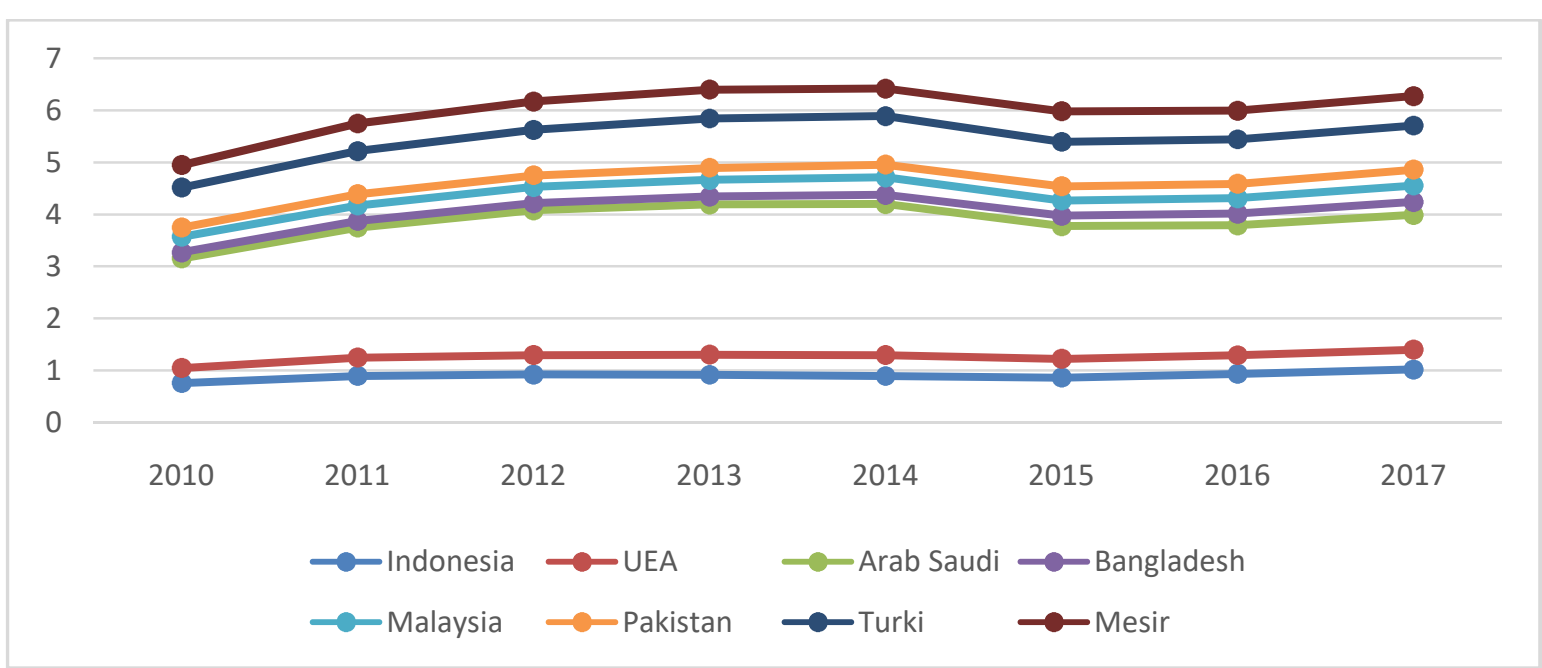

Gambar 1. PDB (Milyar US\$) negara Emerging Market Muslim

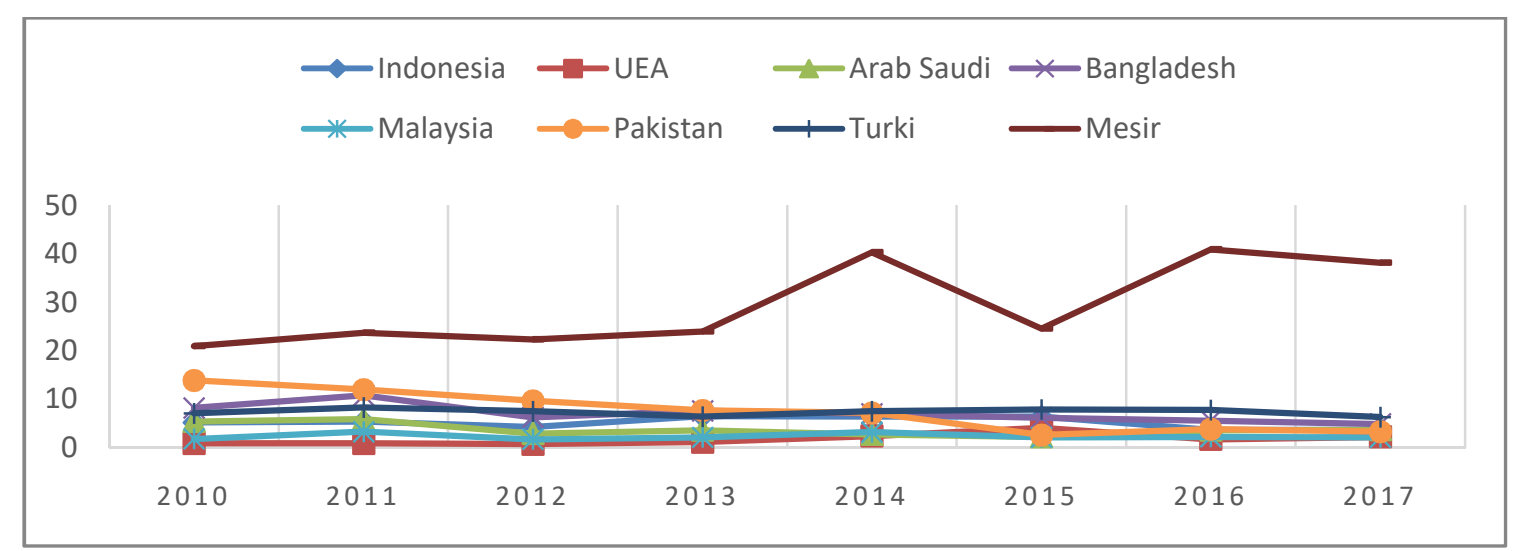

Gambar 2 : Inflasi negara emerging market muslim

Resiko inflasi negara Muslim Emerging market, inflasi Indonesia naik menjadi 5,36\% dari 5,13\% tahun sebelumnya, Arab saudi naik menjadi 5,83\% dari 5,34\% tahun sebelumnya, Bangladesh naik menjadi $11,40 \%$ dari $8,13 \%$ tahun sebelumnya, Malaysia naik menjadi 3,17\% dari 1,62\% tahun sebelumnya, dan Mesir naik menjadi 23,7\% dari $20,9 \%$ tahun sebelumnya. Di negara-negara berpenghasilan rendah, momentum inflasi (tingkat inflasi triwulanan disesuaikan secara triwulanan dinyatakan pada tingkat tahunan) turun drastis sepanjang tahun lalu, dari rata-rata 14 persen di tahun 2011 sampai saat ini turun 1,6 persen di ketiganya bulan sampai September 2012 sebelum memulai tren kenaikan pada kuartal terakhir 2012. Penurunan tajam mencerminkan efek gabungan stabilisasi harga pangan lokal setelah tahun 2011 kenaikan harga terkait kekeringan, pengetatan kebijakan, dan pelonggaran pasokan bahan bakar dan makanan gangguan selama episode gejolak politik di Timur Tengah dan bagian-bagian Sub Sahara Afrika. 
Published July 2019

EKONOMIKAWAN : Jurnal Ilmu Ekonomi dan Studi Pembangunan

ISSN : $1693-7600$ (Print), ISSN : 2598-0157 (Online), http://jurnal.umsu.ac.ld/index.php/ekawan

\section{KAJIAN TEORI}

Ketahanan fundamental dapat dilihat dari teori ekonomi terbuka dengan mengidentifikasikan variabel makro ekonomi, bunga, investasi dan nercaca perdagangan seperti net ekspor, cadangan devisa dan kurs. Model Analisis konsep jangka panjang menggunakan konsep:

$$
\begin{aligned}
& I N F_{t}=\beta_{10} I N F_{t-p}+\beta_{11} T A X_{t-p}+\beta_{12} G O V_{t-p}+\beta_{13} P D B_{t-p}+\beta_{14} I N V_{t-p} \\
& +\beta_{15} \text { KURS }_{t-p}+\beta_{16} S B K_{t-p}+\beta_{17} J U B_{t-p}+\beta+e_{t 1} \\
& T A X_{t}=\beta_{20} T A X_{t-p}+\beta_{21} I N F_{t-p}+\beta_{22} G_{t-p}+\beta_{23} P D B_{t-p}+\beta_{24} I N V_{t-p} \\
& +\beta_{25} K U R S_{t-p}+\beta_{26} S B K_{t-p}+\beta_{27} J U B_{t-p}+\beta+e_{t 2} \\
& \text { GOV }_{t}=\beta_{30} G O V_{t-p}+\beta_{31} T A X_{t-p}+\beta_{32} I N F_{t-p}+\beta_{33} P D B_{t-p}+\beta_{34} I N V_{t-p} \\
& +\beta_{35} K_{U R S_{t-p}}+\beta_{36} S B K_{t-p}+\beta_{37} J U B_{t-p}+\beta+e_{t 3} \\
& P D B_{t}=\beta_{40} P D B_{t-p}+\beta_{41} T A X_{t-p}+\beta_{42} G O V_{t-p}+\beta_{43} I N F_{t-p}+\beta_{44} I N V_{t-p} \\
& +\beta_{45} K U R S_{t-p}+\beta_{46} S B K_{t-p}+\beta_{47} J U B_{t-p}+\beta+e_{t 4} \\
& I N V_{\mathrm{t}}=\beta_{50} I N V_{t-p}+\beta_{51} T A X_{t-p}+\beta_{52} G O V_{\mathrm{t}-p}+\beta_{53} P D B_{t-p}+\beta_{54} I N F_{t-p} \\
& +\beta_{55} K U R S_{t-p}+\beta_{56} S B K_{t-p}+\beta_{57} J U B_{t-p}+\beta+e_{t 5} \\
& \text { KURS }_{t}=\beta_{60} \text { KURS }_{t-p}+\beta_{61} T_{A X}+p+\beta_{62} G_{t-p}+\beta_{63} P D B_{t-p}+\beta_{64} I N V_{t-p} \\
& +\beta_{65} I N F_{t-p}+\beta_{66} S B K_{t-p}+\beta_{67} J U B_{t-p}+\beta+e_{t 6} \\
& S B K_{t}=\beta_{70} S B K_{t-p}+\beta_{71} T A X_{t-p}+\beta_{72} G O V_{t-p}+\beta_{73} P D B_{t-p}+\beta_{74} I N V_{t-p} \\
& +\beta_{75} K_{U R S} S_{t-p}+\beta_{76} I N F_{t-p}+\beta_{77} J U B_{t-p}+\beta+e_{t 7} \\
& I U B_{t}=\beta_{80} J U B_{t-p}+\beta_{81} T A X_{t-p}+\beta_{82} G O V_{t-p}+\beta_{83} P D B_{t-p}+\beta_{84} I N V_{t-p} \\
& +\beta_{85} K U R S_{t-p}+\beta_{86} S B K_{t-p}+\beta_{87} I N F_{t-p}+\beta+e_{t 8}
\end{aligned}
$$

Tabel 1. Variabel Penelitian, Pengukuran dan Skala

\begin{tabular}{|l|l|l|l|}
\hline No & \multicolumn{1}{|c|}{ Variabel } & \multicolumn{1}{c|}{ Pengukuran } & \multicolumn{1}{c|}{ Skala } \\
\hline 1 & Pajak & Milyar Rupiah. & Rasio \\
\hline 2 & Pengeluaran Pemerintah & Milyar Rupiah. & Rasio \\
\hline 3 & Investasi & Milyar US\$ & Rasio \\
\hline 4 & SBK & $\begin{array}{l}\text { Kredit domestik yang diberikan oleh sektor } \\
\text { keuangan(Persen) }\end{array}$ & Rasio \\
\hline 5 & JUB & Milyar Rupiah. & Rasio \\
\hline 6 & Inflasi & Indeks harga konsumen (persen) & Rasio \\
\hline 7 & PDB & Milyar Rupiah. & Rasio \\
\hline 8 & Kurs & Dollar Amerika(US\$) & Rasio \\
\hline
\end{tabular}




\section{Published July 2019}

\section{EKONOMIKAWAN : Jurnal Ilmu Ekonomi dan Studi Pembangunan}

ISSN : 1693-7600 (Print), ISSN : 2598-0157 (Online), http://jurnal.umsu.ac.Id/index.php/ekawan

\section{METODE}

Model panel ARDL digunakan dalam memprediksi fundamental ekonomi dalam menghadapi kondisi ekonomi internal dan eksternal suatu negara (Rusiadi et al., 2018). Panel Autoregresif Distributed Lag (ARDL) Pesaran et al. (2001). Teknik panel ARDL statistik uji yang dapat membandingkan dengan dua nilai kritikal yang asymptotic dengan rumus :

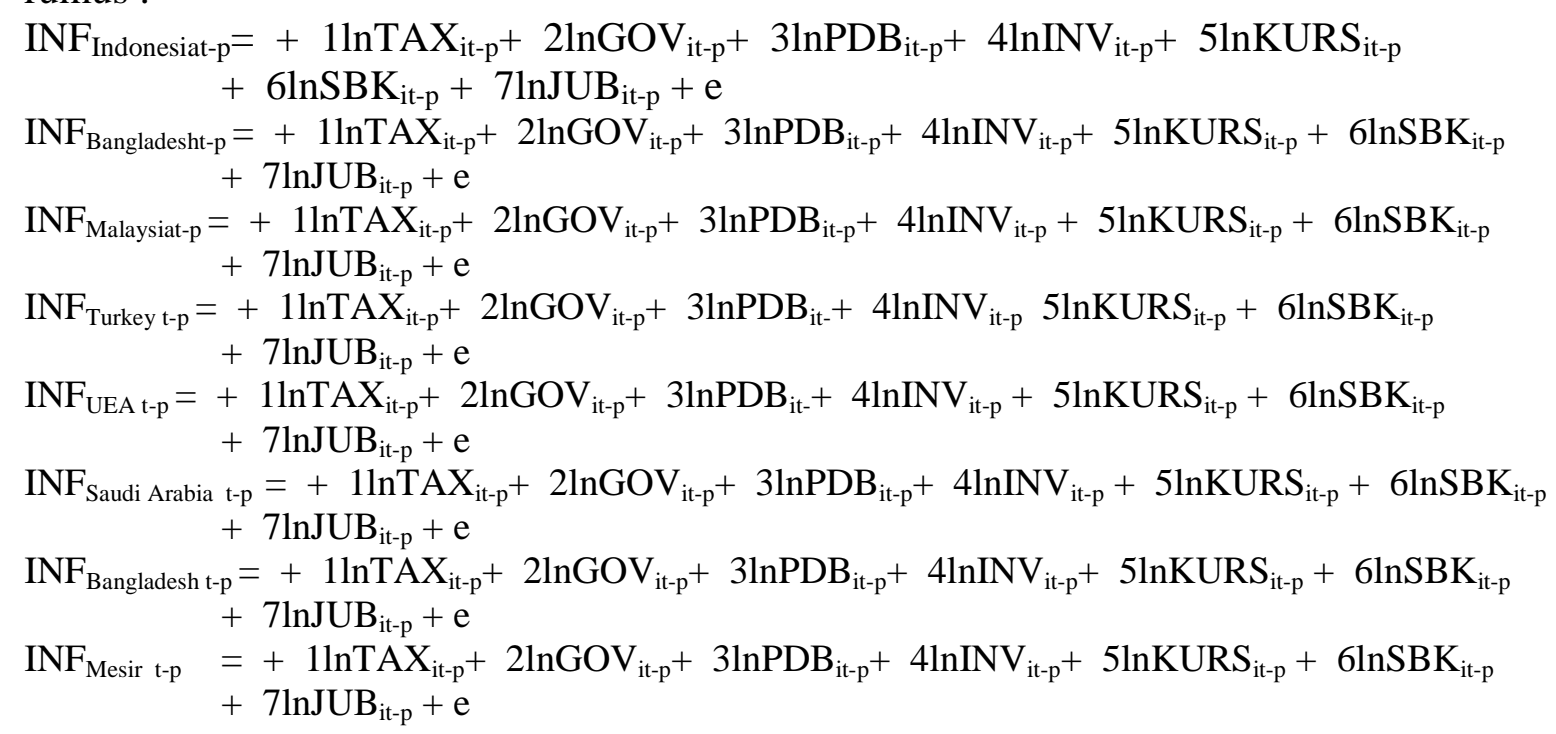

Keterangan :

INF : inflasi (\%), TAX: Pajak (Milyar Rupiah), GOV : Pengeluaran Pemeintah (Milyar Rupiah), PDB : produk domestik bruto (US\$), INV: investasi (US\$), SBK : suku bunga kredit (\%), JUB : jumlah uang beredar (milyar rupiah), KURS: nilai tukar mata uang (US\$), PDB: produk domestic bruto (US\$), e : error term, $\beta$ : koefisien regresi, $\alpha$ : konstanta $\mathrm{p}$ : panjang lag optimal, i: negara observasi (7 negara), $\mathrm{t}$ : banyaknya waktu (8 tahun, 2010 sd 2017).

\section{HASIL DAN PEMBAHASAN}

Pengujian atas panel ARDL harus memiliki dasar slope negatif tingkat signifikan. Nilainya negatif $(-0.78)$ dalam arah probabilitas signifikan $(0,01<0,05)$. Hasil keseluruhan diketahui bahwa yang signifikan dalam jangka panjang mempengaruhi inflasi di negara emerging market muslim yaitu government expenditure, Suku bunga dan jumlah uang beredar. Kemudian dalam jangka pendek jumlah uang beredar yang mempengaruhi stabilitas inflasi. Leadingindicator efektivitas variabel dalam pengendalian stabilitas negara emerging market muslim yaitu jumlah uang beredar (Indonesia, Bangladesh, Malaysia, Pakistan dan UEA, Arab Saudi, mesir dan Turkey) dilihat dari stabilitas short run dan long run, dimana variabel jumlah uang beredar dalam jangka panjang maupun pendek signifikan mengendalikan stabilitas ekonomi. 


\section{Published July 2019}

\section{EKONOMIKAWAN : Jurnal Ilmu Ekonomi dan Studi Pembangunan}

ISSN : 1693-7600 (Print), ISSN : 2598-0157 (Online), http://jurnal.umsu.ac.Id/index.php/ekawan

Leadingindicator efektivitas negara dalam pengendalian stabilitas negara-negara emerging market muslim, yaitu Indonesia, Bangladesh (Pajak, government expenditure, Jumlah uang beredar, suku bunga kredit dan Jumlah uang beredar) dan Malaysia (pajak, government expenditure, investasi dan jumlah uang beredar). Negara lainnya misalnya UEA dan Arab saudi pengendalian stabilitas ekonomi dilakukan oleh pajak, investasi dan jumlah uang beredar, sedangkan Mesir dan Turkey dilakukan melalui jumlah uang beredar. Secara panel ternyata jumlah uang beredar mampu menjadi leadingindicator untuk pengendalian negara Indonesia, Bangladesh, Malaysia, Pakistan, UEA, Arab Saudi, Mesir dan Turkey.

Hasil analisis data panel ARDL dapat dilihat pada tabel 2 berikut ini :

Tabel 2. Output Panel ARDL

\begin{tabular}{|c|c|c|c|}
\hline & Long Run Equation & & \\
\hline TAX & $-0.022710 \quad 0.013360$ & -1.699902 & 0.0946 \\
\hline GOV & -0.2699430 .070792 & -3.813180 & 0.0003 \\
\hline LNPDB & $-0.744731 \quad 0.425516$ & -1.750182 & 0.0855 \\
\hline INV & $-0.002023 \quad 0.148975$ & -0.013582 & 0.9892 \\
\hline LNKURS & -1.0168941 .035407 & -0.982120 & 0.3302 \\
\hline SBK & $0.468207 \quad 0.129963$ & 3.602604 & 0.0007 \\
\hline \multirow[t]{2}{*}{ JUB } & $\begin{array}{lll}-0.046787 & 0.039917\end{array}$ & -1.172116 & 0.0460 \\
\hline & \multicolumn{3}{|l|}{ Short Run Equation } \\
\hline COINTEQ01 & $-0.912921 \quad 0.161860$ & -5.640175 & 0.0000 \\
\hline $\mathrm{D}(\mathrm{INF}(-1))$ & $0.026479 \quad 0.071777$ & 0.368905 & 0.7136 \\
\hline $\mathrm{D}(\mathrm{TAX})$ & -1.0623841 .780055 & -0.596826 & 0.5530 \\
\hline $\mathrm{D}(\mathrm{GOV})$ & $0.062269 \quad 0.176649$ & 0.352500 & 0.7258 \\
\hline $\mathrm{D}(\mathrm{LNPDB})$ & $29.28328 \quad 7.699262$ & 3.803387 & 0.5854 \\
\hline D(INV) & -0.9187380 .890686 & -1.031495 & 0.3067 \\
\hline D(LNKURS) & $25.87371 \quad 7.122522$ & 3.632661 & 0.8406 \\
\hline $\mathrm{D}(\mathrm{SBK})$ & $0.017962 \quad 0.712048$ & 0.025226 & 0.9635 \\
\hline D(JUB) & $-0.044712 \quad 0.031078$ & -1.438688 & 0.0257 \\
\hline $\mathrm{C}$ & $11.64596 \quad 2.993129$ & 3.890899 & 0.0003 \\
\hline
\end{tabular}

Berikut tabel rangkuman hasil panel ARDL: 
Published July 2019

EKONOMIKAWAN : Jurnal Ilmu Ekonomi dan Studi Pembangunan

ISSN : $1693-7600$ (Print), ISSN : 2598-0157 (Online), http://jurnal.umsu.ac.Id/index.php/ekawan

Tabel 3 : Rangkuman Panel ARDL

\begin{tabular}{|l|c|c|c|c|c|c|c|c|c|c|}
\hline & Indonesia & Bangladesh & Malaysia & Pakistan & UEA & $\begin{array}{c}\text { Arab } \\
\text { Saudi }\end{array}$ & Mesir & Turkey & $\begin{array}{c}\text { Short } \\
\text { Run }\end{array}$ & $\begin{array}{c}\text { Long } \\
\text { Run }\end{array}$ \\
\hline Pajak & I & I & I & I & O & I & O & O & O & O \\
\hline GOV & I & I & I & I & O & O & O & O & O & I \\
\hline PDB & O & O & O & O & O & O & O & O & I & O \\
\hline Investasi & O & O & I & O & I & O & O & O & O & O \\
\hline Kurs & O & O & O & O & O & O & O & O & I & O \\
\hline $\begin{array}{l}\text { Bunga } \\
\text { kredit }\end{array}$ & I & I & O & I & O & O & O & O & O & I \\
\hline JUB & I & I & I & I & I & I & I & I & I & I \\
\hline Inflasi & O & O & O & O & O & O & O & O & O & O \\
\hline
\end{tabular}

Sumber : Data diolah, 2019.

Berikut rangkuman stabilitas jangka panjang Negara emerging market muslim :

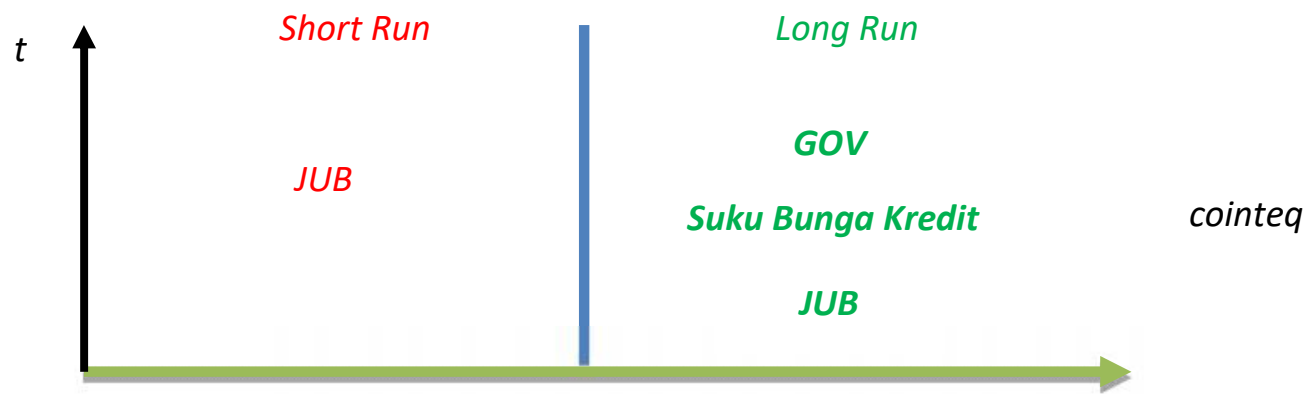

Gambar 3. Prediksi Ketahanan Fundamental Ekonomi Negara Muslim Emerging Market

Leadingindicator negara dalam pengendalian negara emerging market Muslim, yaitu Indonesia, Bangladesh (Pajak, goverment expenditure, uang beredar, suku bunga kredit dan uang beredar) dan Malaysia (pajak, goverment expenditure, investasi dan uang beredar Negara : UEA dan Arab saudi pengendalian stabilitas ekonomi dilakukan oleh pajak, investasi dan uang beredar, sedangkan Mesir dan Turkey dilakukan melalui uang beredar. Negara Indonesia masih kuat dalam mengendalikan stabilitas harga melalui terjaganya stabilitas kurs. Negara bangladesh masih kuat dalam mengendalikan stabilitas harga melalui terjaganya ketahanan uang beredar. Negara Malaysia masih kuat dalam mengendalikan stabilitas harga (Nguyen, 2015). Perkembangan uang beredar sebagai leadingindicator ketahanan ekonomi di Indonesia, Bangladesh, Malaysia, Pakistan dan UEA, Arab Saudi, Turkey. Leadingindicator pengendalian stabilitas negara emerging market yaitu uang beredar (Indonesia, Bangladesh, Malaysia, Pakistan dan UEA, Arab Saudi, Turkey). Nwaobi (2014) menyatakan uang beredar berpengaruh ketahanan fundamental. Mgadmi (2017) uang beredar positif terhadap fundamental ekonomi (2016) kemudian Hussain (2014), dan didukung Chrigue (2015). Senbet (2016) Sekhposyan (2011), dan Abubakar (2013) serta (Rusiadi; Novalina, 2018). 
Published July 2019

EKONOMIKAWAN : Jurnal Ilmu Ekonomi dan Studi Pembangunan

ISSN : $1693-7600$ (Print), ISSN : 2598-0157 (Online), http://jurnal.umsu.ac.Id/index.php/ekawan

\section{SIMPULAN}

Secara panel ternyata uang beredar menjadi leading indicator untuk pengendalian negara Indonesia, Bangladesh, Malaysia, Pakistan dan UEA, Arab Saudi, Turkey. Dan posisinya stabil dalam short run dan long run. Leading indicator utama efektivitas variabel dalam pengendalian stabilitas negara emerging market muslim yaitu investasi dilihat dari stabilitas short run dan long run, dimana variabel jumlah uang beredar dalam jangka panjang maupun pendek signifikan dalam mengendalikan stabilitas ekonomi.

\section{DAFTAR PUSTAKA}

Ginting, Mulianta Ari. (2015). Pengaruh Nilai Tukar terhadap Ekspor di Indonesia. Buletin Ilmiah Litbang Perdagangan. Vol.7 No.1.

Hasibuan, Saida dan Pratomo, Aria, Wahyu. (2012). Mekanisme Transmisi Kebijakan Moneter Melalui Suku Bunga SBI Sebagai Sasaran Operasional Kebijkan Moneter dan Variabel makroekonomi Indonesia. Jurnal Ekonomi dan Keuangan. Vol.1 No.12.

Mgadmi, N. and Chrigui, Z. (2017). Monetary Policy's Transmission Channels In Tunisia: SVAR Model Validation.Journal of Business and Management Research, 8 (2015) 189-200 p-ISSN : 2356-5756 / e-ISSN: 2356-5764.

Natsir, M. (2014). Peranan Jalur Suku Bunga Dalam Mekanisme Transmisi Kebijakan Moneter Di Indonesia. Dosen Fe \& Program Pascasarjana Unhalu Kendari. Tesis. Tidak Dipublikasikan.

Nguyen, Boateng, (2013). "The Impact Of Excess Reserves Beyond Precautionary Levels On Bank Lending Channels In China”, Journal Of International Financial Markets, Institutions And Money 26, 358-377

Nwaobi, Godwin Chukwudum. 2014.The Balance of Payments as a Monetary Phenomenon: an Econometric Case Study of Nigeria". Papers by JEL Classification. pages 1-34.

Oguanobi, C.R., Akamobi, A.A., and Agu, C.C. (2014). Cross-Border Transmission Of Interest Rate Shocks: A VAR Analysis Of The Nigerian Economy. Journal of Economics and Sustainable Development Vol.5, No.7, 2014.

Rusiadi; Novalina, A. (2018). Mone Does Maintain the Price and Poverty Stability is Effective? Jejak Jurnal Ekonomi Dan Kebijakan Journal of Economics and Policy, 11(102), 78-78.

Rusiadi, Nova. (2018). Dependence of poverty dependence on Indonesian economic fundamentals: Sfavar approach. International Journal of Civil Engineering and Technology, 9(6).

Sheefeni, J.P., and Kalikeka. M. (2013). Interest Rate Channel And Monetary Transmission In Zambia.Journal Of Emerging Issues In Economics, Finance And Banking (Jeiefb) Volume:2 No.6 December 2013.

Soares, R. (2011). Assessing Monetary Policy in the Euro Area: a Factor-Augmented VAR Approach. Banco de Portugal Working Paper, (11).

Surjaningsih, Dewati, W., , N., dan Chawwa, T. (2015). Revisiting Transmisi Kebijakan Moneter: Pendekatan VAR dan Panel Data. Laporan Hasil Penelitian Bank Indonesia, (19). 
Vymyatnina.Y. (2011). Monetary Policy Transmission And Bank Of Russia Monetary Policy. Department of Economics European University at St Petersburg, Working paper Ec-02/05.

Wimanda, R.E., Maryaningsih, N., Nurliana, L and Satyanugroho, R. (2014). Evaluasi Transmisi Bauran Kebijakan Bank Indonesia. Working Paper WP/ 03/ 2014, Bank Indonesia. 